\title{
AMINO ACID ANALOG TOXICITY IN PRIMARY RAT NEURONAL AND ASTROCYTE CULTURES: IMPLICATIONS FOR PROTEIN MISFOLDING AND TDP-43 REGULATION
}

\author{
Kalavathi Dasuria ${ }^{\mathrm{a}}$ Philip J. Ebenezer ${ }^{\mathrm{a}}$, Romina M. Uranga ${ }^{\mathrm{b}}$, Elena Gavilán ${ }^{\mathrm{c}}$, Le Zhang ${ }^{\mathrm{a}}$, Sun \\ OK Fernandez-Kim ${ }^{a}$, Annadora J. Bruce-Keller ${ }^{a}$, and Jeffrey N. Keller ${ }^{a, \ddagger, \dagger}$ \\ aPennington Biomedical Research Center, Louisiana State University System, Baton Rouge, LA \\ 70808-4124, USA \\ bInstituto de Investigaciones Bioquímicas de Bahía Blanca, Universidad Nacional del Sur and \\ Consejo Nacional de Investigaciones Científicas y Técnicas, Bahía Blanca, Argentina \\ 'Departamento de Bioquímica, Bromatología, Toxicología y Medicina Legal, Facultad de \\ Farmacia, Universidad de Sevilla, Seville, Spain
}

\section{Abstract}

Amino acid analogs promote translational errors that result in aberrant protein synthesis, and have been used to understand the effects of protein misfolding in a variety of physiological and pathological settings. TDP-43 is a protein that is linked to protein aggregation and toxicity in a variety of neurodegenerative diseases. In this study we exposed primary rat neurons and astrocyte cultures to established amino acid analogs (Canavanine and Azetidine-2-carboxylic acid), and observed both cell types undergo a dose-dependent increase in toxicity, with neurons exhibiting a greater degree of toxicity as compared to astrocytes. Neurons and astrocytes exhibited similar increases in ubiquitinated and oxidized protein following analog treatment. Analog treatment increased Heat shock protein (Hsp) levels in both neurons and astrocytes. In neurons, and to a lesser extent astrocytes, the levels of TDP-43 increased in response to analog treatment. Taken together, these data indicate that neurons exhibit preferential toxicity and alterations in TDP-43, in response to increased protein misfolding, as compared to astrocytes.

\section{Keywords}

Aging; Alzheimer's disease; cell death; neurodegeneration; neurotoxicity; protein aggregation; ubiquitin

\section{INTRODUCTION}

Protein misfolding and protein aggregation are characteristic features of many neurodegenerative diseases including Alzheimer's disease (AD), Parkinson's disease (PD), frontotemporal lobar degeneration (FTLD), and amyotrophic lateral sclerosis (ALS). The amino acid analogs canavanine (Can) and azetidine-2-carboxylic acid (AZC) mimic the

\footnotetext{
${ }^{\ddagger}$ Corresponding author: Dr Jeffrey N. Keller, Professor, Associate Executive Director of Basic Research, Director, Institute for Dementia Research and Prevention, Pennington Biomedical Research Center, LSU System, 6400 Perkins Road, Baton Rouge, LA 70808-4124, (P) 225-763-3190; (F) 225-763-3193;, (E) jeffrey.keller@ pbrc.edu.

${ }^{\dagger}$ This work was supported by grants from the NIA (AG029885, AG025771) and the Hibernia National Bank/Edward G Schlieder Chair (J.N.K.).

The authors declare that they do not have any conflict of interests.
} 
natural amino acids arginine and proline, and are incorporated into nascent polypeptides promoting irreversible abnormal protein confirmation (Fowden and Richmond, 1963; Fowden et al., 1967; Bessonov et al., 2010; Grant et al 1975; Zagari et al., 1990; Rosenthal et al., 1989; Prouty et al., 1975; Rodgers and Shiozawa, 2008) and alterations in global protein synthesis ( Qian et al., 2010; Kretz-Remy, et al., 1998). Can and AZC can therefore be used to mimic the increased levels of abnormal proteins observed in aging cells, and potentially model increased protein misfolding observed in a variety of neurodegenerative conditions.

In order to prevent proteotoxicity from increased protein misfolding, cells rely on the function of numerous heat shock proteins (Hsps) including Hsp70 and Hsp40 (Trottel et al., 2002; Li et al., 1985; Watowich and Morimoto, 1988; Hightower 1991; Ananthan et al., 1986; Barrett et al., 2004). Both Can and AZC have been shown to induce a variety of Hsps (Trottel et al., 2002; Li et al., 1985; Watowich and Morimoto, 1988; Qian et al., 2010; Kozutsumi et al., 1998; Thomas and Mathews, 1984), consistent with both analogs promoting proteotoxic stress. Currently it is not known whether neurons and astrocytes differ in regards to their sensitivity to toxicity or Hsp induction in response to amino acid analogs such as Can and AZC.

A number of abnormal proteins have been shown to accumulate in neurodegenerative diseases such as AD, PD, and FTLD ( Uversky 2008; Koo et al., 1999; Agorogiannis et al., 2004; Reddy, 2006; Meridith 2005; Ross and Poirier, 2004; Zhu et al., 2005) suggesting the genesis of proteotoxic stress. Recent studies have suggested an important role for TAR DNA-binding protein of 43-kDa (TDP-43) in modulating proteotoxicity associated with increased protein misfolding (Neumann 2006; Chen-plotkin et al., 2010). TDP-43 is abundantly expressed in neurons and glia, and has been identified as a major component of ubiquitinated neuronal cytoplasmic inclusions (NCI) and neuronal intranuclear inclusions. Full length TDP-43, as well as cleavage products of $\sim 25 \mathrm{kDa}$ and $35 \mathrm{kDa}$, are observed in ALS and FTLD (Zhang et al., 2009; Chanson et al., 2010; Ritson et al., 2010; Kabashi et al., 2008; Barmada et al., 2010; Halawani and Latterich, 2006; Dalal et al., 2004). Currently, it is not known whether analogs such as Can and AZC modulate TDP-43 homeostasis in primary neuron and astrocyte cultures.

In the present paper, we demonstrate that treatment of primary rat neurons and astrocytes results in a dose-dependent increase in cell death, with neurons being more vulnerable to the toxicity of Can and AZC. The preferential increase in neuronal toxicity did not appear to be linked to differences in ubiquitinated proteins, oxidized proteins, or Hsp induction. Amino acid analogs induced increased levels of TDP-43 and its cleavage products. Taken together these data have implications for understanding how increased levels of aberrant proteins during aging and neurodegenerative disease contribute to neuronal death and dysfunction in the brain.

\section{MATERIALS AND METHODS}

\section{Materials}

The antibodies to $\beta$-actin (SC-47778) and ubiquitin (SC - 8017) were purchased from Santa Cruz Biotechnology Company (Santa Cruz, CA, USA). The antibodies to TDP-43 (3448S) were purchased from Cell Signaling Technology, Inc.(Cambridge, MA, USA). The antibodies to Hsp70 (SPA-810D) and Hsp40 (SPA-400D) were purchased from Enzo Life Sciences International, Inc. (Plymouth Meeting, PA). Oxyblot kit was purchased from Millipore Company (Billerica, MA, USA). All the chemicals including Hoechts 33342 (bisBenzamide trihydrochloride) staining, Triton X-100, protease inhibitor mix, EDTA, DNase I, AZC (L-Azetidine-2-carboxylic acid) and L-Canavanine were purchased from 
Sigma-Aldrich, Corp. (St. Louis, MO, USA). All electrophoresis and immunoblot reagents were purchased from Bio-Rad Laboratories (Hercules, CA, USA). All cell culture supplies were obtained from GIBCO Life Sciences (Gaithersburg, MD, USA). The BCA reagent was purchased from Thermo Scientific, Inc. (Pittsburgh, PA, USA).

\section{Establishment and maintenance of primary neuron and astrocyte cultures: treatment with analogs}

Neuronal cultures were established as described previously by our laboratory (Ding et al., 2006; Dasuri et al.,, 2010b, Ebenezer et al.,, 2010). Briefly, primary rat cortical neuronal cells were cultured from E18 Sprague-Dawley rats and maintained in $5 \% \mathrm{CO} 2$ at $37^{\circ} \mathrm{C}$ in MEM or Neurobasal medium containing $5 \%$ fetal bovine serum (heat inactivated), N2 supplement, B27 supplement, and 1\% antibiotic. Cells were used in experiments between days 6-9 (Neurons) and 12-15 (Astrocytes) post plating. Rat astrocyte cultures were established from E18 Sprague-Dawley rats as described previously by our laboratory (Ding et al., 2006; Dasuri et al.,, 2010b, Ebenezer et al.,, 2010). Astrocytes were maintained in 5\% $\mathrm{CO}_{2}$ at $37^{\circ} \mathrm{C}$ in MEM medium containing $5 \%$ fetal bovine serum (heat inactivated), N2 supplement and $1 \%$ antibiotic solution. All animals were utilized in accordance with IACUC approved protocols at the Pennington Biomedical Research Center. For the analysis of protein levels following analog treatment, the primary cultures of neurons and astrocytes were treated with various concentrations of analogs (AZC or Can) and the pelleted cells were frozen at $-80^{\circ} \mathrm{C}$ until further use.

\section{Analysis of cell viability}

Cell survival was determined by quantification of apoptotic and necrotic nuclei using Hoechts 344 staining as described previously (Keller et al., 1998; Ding et al., 2006; Dasuri et al., 2010b, Ebenezer et al.,, 2010). Briefly, Neuronal and astrocyte cells were treated with increasing concentrations of analogs (AZC or Can) for 3 hours or with $5 \mathrm{mM}$ of analog for the indicated time intervals. The treated cells were stained with the fluorescent DNAbinding dye Hoechts 344 at a concentration of $1 \mu \mathrm{g} / \mu \mathrm{l}$, and the percentage of viable cells were determined by counting the number of dead cells (condensed and fragmented nuclei) using a fluorescence microscope equipped with a $32 \mathrm{X}$ objective. Additional confirmation of cell viability was determined using MTT reduction as a measure of cell viability as reported previously (Kruman et al., 1997; Ding et al., 2006; Dasuri et al.,, 2010b, Ebenezer et al., 2010).

\section{Protein estimation}

Protein concentration of the cell lysates made in cell lysis buffer was estimated using BCA (Thermo Scientific) reagent as described by the manufacturer.

\section{Western blotting}

The protein samples were analyzed by SDS-PAGE and immunoblotted with specified antibodies as described previously by our laboratory (Dasuri et al., 2010a).

\section{Analysis of protein oxidation levels}

Protein carbonyl levels were analyzed using Oxyblot kit (Millipore) as described by the manufacturer. Briefly, $10 \mu \mathrm{g}$ of protein lysate was derivatized with 2, 4dinitrophenylhydrazone, (DNPH) and then the derivatized products were detected by the Western blot analysis as described by the manufacturer. 


\section{Triton X-100 fractionation of cell lysates and analysis}

Triton X-100 fractionation was done as described by our laboratory (Dasuri et al., 2010b). Briefly, Cells were suspended in extraction buffer $(150 \mu \mathrm{l})$ containing $50 \mathrm{mM}$ Tris- $\mathrm{HCl}$, $\mathrm{pH}-7.4,150 \mathrm{mM} \mathrm{NaCl}$, and $1 \mathrm{mM}$ EDTA, $1 \%$ triton X-100, protease inhibitor cocktail and DNase I (buffer A). The protein lysates were incubated for 30 minutes with shaking at $4^{\circ} \mathrm{C}$. Then the triton X-100 soluble and insoluble fractions were separated by centrifugation for 20 minutes at $14,000 \mathrm{X} g$. The protein levels in triton X-100 soluble and insoluble fractions were estimated and equal amounts of protein were used for the analysis of protein levels using the western blotting.

\section{Statistics}

Statistical analyses were conducted using the Prism 3.0 software (GraphPad Software, San Diego, CA). Student's two-tailed $t$-test was used to determine whether observed differences were statistically significant $(\mathrm{p}<0.05)$.

\section{RESULTS}

\section{Neuronal cells exhibit increased sensitivity to amino acid analog toxicity}

Canavanine and AZC are amino acid analogs which incorporate into newly synthesized proteins resulting in protein misfolding and the accumulation of abnormal proteins (Kelley and Schlesinger, 1978; Ananthan et al., 1986; Hightower 1980). In order to study the relative susceptibilities of primary rat neuronal and astrocyte cultures to the toxicity of misfolded and abnormal proteins, we conducted studies analyzing the acute toxicity of Can and AZC. We have observed that AZC and Can promoted a dose-dependent increase in cell death in both neurons and astrocytes (Figures $1 \& 2$ ). The toxicity of AZC and Can was nearly identical, with both agents observed to induce more pronounced cell death in neurons as compared to (Figures $1 \& 2$ ) at every dose analyzed. Treatment with analogs induced a time dependent increase in cell death, with neurons observed to undergo more severe loss of viability than astrocytes (Figure $1 \& 2$ ), at every dose analyzed.

\section{Neuronal and astrocyte cells exhibit higher level of ubiquitinated and oxidized proteins following amino acid analog treatment}

To overcome the accumulation of abnormal or misfolded proteins cells rely on the function of multiple proteolytic pathways, including ubiquitin-dependent pathways (Hershko and Ciechanover, 1992; Hochstrasser 1992; Navon and Ciechanover, 2009). In our analysis, we observed that Can and AZC increased the levels of ubiquitinated protein in both neurons and astrocytes (Figure 3). Although much more variable, amino acid analog treatment also increased the levels of oxidized proteins in both neurons and astrocytes (Figure 3).

\section{Amino acid analog treatment increases the levels of Heat shock protein (Hsp) in neurons and astrocytes}

Next, we sought to elucidate whether Can and AZC treatment altered the levels of Hsps in neurons and astrocytes. In our studies we observed that both neurons and astrocytes exhibited increases in Hsp70 and Hsp40 levels following Can and AZC treatment (Figure 4). See supplementary Figure 1 for quantification of blots from Figure 4.

\section{Effect of amino acid analog treatment on the levels of TDP-43 in neurons and astrocytes}

In order to determine if amino acid analog treatment alters the levels of TDP-43 we conducted studies looking at the total levels of TDP-43, in neurons and astrocytes. In this analysis we observed that the total levels of TDP-43 were robustly increased in neurons (Figure 5). In astrocytes increases were transient or occurred to a lesser degree (Figure 5), 
than was observed in neuronal cultures. Analysis revealed that the levels of the known $~ 35$ $\mathrm{kDa}$ cleavage product of TDP-43 were selectively observed in neurons treated with the highest concentrations of amino acid analogs, and not observed in astrocyte cultures (Figure 5). Please see supplementary Figure 2 for quantification of TDP-43.

\section{DISCUSSION}

Amino acid analogs AZC and Can are used to induce protein misfolding (Goldberg and Dice, 1974; Trotter et al., 2002) It is known that AZC causes changes in the confirmation of the protein back bone leading to functional alterations in multiple proteins (Bessonov et al., 2010; Trotter et al., 2001;Trotter et al., 2002; Hoshikawa et al., 2003). In our study we show for the first time that AZC and Can both cause a loss of cell viability in primary CNS cultures. These post-mitotic neurons in the current study exhibited dramatically elevated sensitivity to the toxicity associated with increased protein misfolding, when compared to mitotic astrocyte cultures. Neurons are known to be more vulnerable than astrocytes to a variety of stressors relevant to aging including oxidative stressors and proteasome inhibitors (Keller et al., 1999, 2000; Ding et al., 2006; Dasuri et al., 2010b; Schmuck et al., 2002; Watts et al., 2005). This increased vulnerability may be due in part to the increased propensity of neurons to undergo increases in protein hydrophobicity following proteasome inhibitor treatment (Dasuri et al., 2010a), as compared to astrocyte cultures. The key to understanding the basis for this toxicity likely resides in defining if toxicity is mediated by gross abnormalities in the proteome, or conversely mediated by selective or key perturbations within the proteome, during periods of increased protein misfolding.

In the current study we observed that the levels of ubiquitinated and oxidized proteins are increased in both neurons and astrocytes following amino acid analog treatment. The increase in both ubiquitinated and oxidized proteins were similar in both neurons and astrocytes, suggesting that the increased neuron death in neurons as compared to astrocyte cultures, is not likely mediated by gross increases in either ubiquitinated or oxidized proteins. Presumably, the misfolding of proteins by AZC and Can treatment results in their rapid ubiquitination, with the increase in ubiquitinated proteins in the present study consistent with the proteolytic pathways responsible for ubiquitinated protein degradation being overwhelmed or inhibited following amino acid analog treatment. In our search of the literature, this study appears to be the first to demonstrate amino acid analogs are capable of increasing the levels of oxidized protein in any cell type. Neither AZC or Can would be expected to be capable of producing reactive oxygen species, suggesting that the increased levels of oxidized protein in the current study are due to the misfolded proteins themselves being more vulnerable to the endogenous oxidative stressors in both neurons and astrocytes in culture. Alternatively, the increased protein misfolding induced by both AZC and Can may indirectly increase oxidative stress within both neurons and astrocytes. For example, misfolding (and presumably loss of function) of antioxidant enzymes and key cell signaling components, results in amino acid analogs promoting increases in oxidized proteins by shifting the intracellular environment to a pro-oxidant environment. Interestingly, previous studies have implied a role for increased reactive oxygen species as a mechanism for amino acid analog-induced increases in NFkB activation (Kretz-Remy et al., 1998).

Our results suggest that increased protein misfolding in the brain during aging and in a variety of neurodegenerative conditions promotes neurocognitive abnormalities through direct effects on neurons, as well as indirect mechanisms. The direct mechanisms relate to the acute neurotoxicity and neuron death, as observed in the present study. Alternatively, it is likely the protein misfolding in the astrocytes in the current study is sufficient to promote the induction of chronic inflammatory signaling, which indirectly is sufficient to promote neurocognitive abnormalities based on their effects on neurons. 
Neurons and astrocytes exhibited similar increases in Hsp70 and Hsp40 following amino acid analog treatment, even though neurons underwent preferential cell death in response to amino acid analog treatment. These data suggest that perturbations in Hsp levels are not principle modulators of cell death following acute increases in protein misfolding. Such data imply that Hsps are potentially overwhelmed or insufficient in this model of toxicity, or conversely raise the possibility of protein misfolding being capable of initiating cell death independent of Hsp regulated events. Studies are currently underway to elucidate which of these scenarios is most relevant to neuron death following amino acid analog treatment.

Interestingly, in the current study it was observed that increases in the potentially TDP-43 protein were observed in neurons following amino acid analog treatment. Based on our survey of the literature this appears to be the first report of amino acid analogs being sufficient to induce TDP-43 levels in any cell type. This study suggest that TDP-43 expression, and the generation of the $\sim 35 \mathrm{kDa}$ TDP- 43 fragment is rapidly induced in neurons following increases in protein misfolding. These data suggest that increases in protein misfolding in FTLD, ALS, and AD may be the basis for TDP-43 alterations observed in each of those conditions. Such increases may arise as the result of the activation of stress kinase pathways or other signal transduction cascades in response to misfolding, or may result from the interactions of misfolded proteins with TDP-43. Studies are currently underway to elucidate the specific mechanism, particularly in light of the potential for TDP-43 to participate in neurodegenerative processes in a variety of pathological conditions. We do not believe that TDP-43 alterations are the primary source of toxicity in the present study, but rather want to highlight our data demonstrating amino acid analogs are capable of promoting TDP-43 alterations.

Our studies raise the possibility of specific proteins potentially playing an important role in the neurodegenerative process following elevations in protein misfolding. Specifically, the current study suggest a role for increased TDP-43 mediating the toxicity of increased protein misfolding. The mechanisms responsible for TDP-43 neurotoxicity have not been firmly elucidated, although previous studies have provided data linking TDP-43 in cytoplasmic inclusions as mediators of neurodegeneration (Neumann et al., 2006; Arai et al., 2006Sasaki et al., 2010; Barmada et al., 2010). In the current study we observed that analog treatment resulted in increased levels of insoluble TDP-43 (data not shown), consistent with the genesis of inclusions, although more data is needed to firmly elucidate this aspect of TDP-43 pathology in the current model.

Previous studies in our laboratory have demonstrated that the ability of insults which increase protein misfolding (proteasome inhibitors) to induce neuron death, is dependent on declines in protein synthesis (Ding et al., 2006). This has been extrapolated to generate a model where protein synthesis is decreased in neurons during periods of increased protein misfolding as a means of protecting the cell (Ding et al., 2007). However, prolonged protein synthesis in this model transitions from being neuroprotective to neurotoxic, as essential proteins are not generated or replaced due to the impairment in protein synthesis (Ding et al., 2007). Understanding the changes in protein synthesis which occur in the current model are currently underway, and when placed in the context of TDP-43 alterations, may help to increase our understanding of TDP-43 pathogenesis.

\section{Supplementary Material}

Refer to Web version on PubMed Central for supplementary material. 


\section{Acknowledgments}

This work was supported by grants from the NIA (AG029885, AG025771) and the Hibernia National Bank/Edward G Schlieder Chair (J.N.K.).

\section{Abbreviations}
Can
Canavanine
AZC
Azetidine-2-carboxylic acid

\section{References}

Agorogiannis EI, Agorogiannis GI, Papadimitriou A, Hadjigeorgiou GM. Protein misfolding in neurodegenerative diseases. N europathol Appl Neurobiol. 2004; 30:215-224.

Ananthan J, Goldberg AL, Voellmy R. Abnormal proteins serve as eukaryotic stress signals and trigger the activation of heat shock genes. Science. 1986; 232:522-524. [PubMed: 3083508]

Arai T, Hasegawa M, Akiyama H, Ikeda K, Nonaka T, Mori H, Mann D, Tsuchiya K, Yoshida M, Hashizume Y, Oda T. TDP-43 is a component of ubiquitin-positive tau-negative inclusions in frontotemporal lobar degeneration and amyotrophic lateral sclerosis. Biochem Biophys Res Commun. 2006; 351:602-611. [PubMed: 17084815]

Barmada SJ, Skibinski G, Korb E, Rao EJ, Wu JY, Finkbeiner S. Cytoplasmic mislocalization of TDP-43 is toxic to neurons and enhanced by a mutation associated with familial amyotrophic lateral sclerosis. J Neurosci. 2010; 30:639-649. [PubMed: 20071528]

Barrett MJ, Alones V, Wang KX, Phan L, Swerdlow RH. Mitochondria-derived oxidative stress induces a heat shock protein response. J Neurosci Res. 2004; 78:420-429. [PubMed: 15389841]

Bessonov K, Bamm VV, Harauz G. Misincorporation of the proline homologue Azetidine (azetidine-2-carboxylic acid) into recombinant myelin basic protein. Phytochemistry. 2010; 71:502507. [PubMed: 20064647]

Chanson JB, Echaniz-Laguna A, Vogel T, Mohr M, Benoilid A, Kaltenbach G, Kiesmann M. TDP43positive intraneuronal inclusions in a patient with motor neuron disease and Parkinson's disease. Neurodegener Dis. 2010; 7:260-264. [PubMed: 20197650]

Chen-Plotkin AS, Lee VM, Trojanowski JQ. TAR DNA-binding protein 43 in neurodegenerative disease. Nat Rev Neurol. 2010; 6:211-220. [PubMed: 20234357]

Dalal S, Rosser MF, Cyr DM, Hanson PI. Distinct roles for the AAA ATPases NSF and p97 in the secretory pathway. Mol Biol Cell. 2004; 15:637-648. [PubMed: 14617820]

Dasuri K, Ebenezer P, Zhang L, Fernandez-Kim SO, Bruce-Keller AJ, Markesbery WR, Keller JN. Increased protein hydrophobicity in response to aging and Alzheimer disease. Free Radic Biol Med. 2010a; 48:1330-1337. [PubMed: 20188163]

Dasuri K, Ebenezer PJ, Zhang L, Fernandez-Kim SO, Uranga RM, Gavilán E, Di Blasio A, Keller JN. Selective vulnerability of neurons to acute toxicity after proteasome inhibitor treatment: implications for oxidative stress and insolubility of newly synthesized proteins. Free Radic Biol Med. 2010b; 49:1290-1297. [PubMed: 20678570]

Ding Q, Dimayuga E, Markesbery WR, Keller JN. Proteasome inhibition induces reversible impairments in protein synthesis. FASEB J. 2006; 20:1055-1063. [PubMed: 16770004]

Ding Q, Cecarini V, Keller JN. Interplay between protein synthesis and degradation in the CNS: physiological and pathological implications. Trends Neurosci. 2007; 30:31-36. [PubMed: 17126920]

Ebenezer PJ, Weidner AM, LeVine H 3rd, Markesbery WR, Murphy MP, Zhang L, Dasuri K, Fernandez-Kim SO, Bruce-Keller AJ, Gavilán E, Keller JN. Neuron specific toxicity of oligomeric amyloid- $\beta$ : role for JUN-kinase and oxidative stress. J Alzheimers Dis. 2010; 22:839-848. [PubMed: 20858948]

Fowden L, Lewis D, Tristram H. Toxic amino acids: their action as antimetabolites. Adv Enzymol Relat Areas Mol Biol. 1967; 29:89-163. [PubMed: 4881886] 
Fowden L, Richmond MH. Replacement of proline by azetidine-2- carboxylic acid during biosynthesis of protein. Biochim Biophys Acta. 1963; 71:459-461.

Goldberg AL, Dice JF. Intracellular protein degradation in mammalian and bacterial cells. Annu Rev Biochem. 1974; 43:835-869. [PubMed: 4604628]

Grant MM, Brown AS, Corwin LM, Troxler RF, Franzblau C. Effect of L-azetidine 2-carboxylic acid on growth and proline metabolism in Escherichia coli. Biochim Biophys Acta. 1975; 404:180187. [PubMed: 1101962]

Halawani D, Latterich M. p97: The cell's molecular purgatory? Mol. Cell. 2006; 22:713-717.

Hershko A, Ciechanover A. The ubiquitin system for protein degradation. Annu Rev Biochem. 1992; 61:761-807. [PubMed: 1323239]

Hightower LE. Cultured animal cells exposed to amino acid analogues or puromycin rapidly synthesize several polypeptides. J Cell Physiol. 1980; 102:402-427.

Hightower LE. Heat shock, stress proteins, chaperones, and proteotoxicity. Cell. 1991; 66:191-197. [PubMed: 1855252]

Hochstrasser M. Ubiquitin and intracellular protein degradation. Curr Opin Cell Biol. 1992; 4:10241031. [PubMed: 1336669]

Hoshikawa C, Shichiri M, Nakamori S, Takagi H. A nonconserved Ala401 in the yeast Rsp5 ubiquitin ligase is involved in degradation of Gap1 permease and stress-induced abnormal proteins. Proc Natl Acad Sci U S A. 2003; 100:11505-11510. [PubMed: 14500784]

Kabashi E, Valdmanis PN, Dion P, et al. TARDBP mutations in individuals with sporadic and familial amyotrophic lateral sclerosis. Nat Genet. 2008; 40:572-574. [PubMed: 18372902]

Keller JN, Hanni KB, Markesbery WR. 4-hydroxynonenal increases neuronal susceptibility to oxidative stress. J Neurosci Res. 1999; 58:823-830. [PubMed: 10583913]

Keller JN, Kindy MS, Holtsberg FW, St Clair DK, Yen HC, Germeyer A, Steiner SM, Bruce-Keller AJ, Hutchins JB, Mattson MP. Mitochondrial manganese superoxide dismutase prevents neural apoptosis and reduces ischemic brain injury: suppression of peroxynitrite production, lipid peroxidation, and mitochondrial dysfunction. J Neurosci. 1998; 18:687-697. [PubMed: 9425011]

Kelley PM, Schlesinger MJ. The effect of amino acid analogues and heat shock on gene expression in chicken embryo fibroblasts. Cell. 1978; 15:1277-1286. [PubMed: 569556]

Koo EH, Lansbury PT Jr, Kelly JW. Amyloid diseases: abnormal protein aggregation in neurodegeneration. Proc Natl Acad Sci USA. 1999; 96:9989-9990. [PubMed: 10468546]

Kozutsumi Y, Segal M, Normington K, Gething MJ, Sambrook J. The presence of malfolded proteins in the endoplasmic reticulum signals the induction of glucose-regulated proteins. Nature. 1988; 332:462-464. [PubMed: 3352747]

Kretz-Remy C, Bates EE, Arrigo AP. Amino acid analogs activate NF-kappaB through redoxdependent IkappaB-alpha degradation by the proteasome without apparent IkappaB-alpha phosphorylation. Consequence on HIV-1 long terminal repeat activation. J Biol Chem. 1998; 273:3180-3191. [PubMed: 9452429]

Kruman I, Bruce AJ, Bredesen DE, Waeg G, Mattson MP. Evidence that 4- Hydroxynonenal Mediates Oxidative Stress- Induced Neuronal Apoptosis. J Neurosci. 1997; 17:5089-5100. [PubMed: 9185546]

Li GC, Laszlo A. Amino acid analogs while inducing heat shock proteins sensitize CHO cells to thermal damage. J Cell Physiol. 1985; 122:91-97. [PubMed: 3965486]

Meredith SC. Protein denaturation and aggregation: Cellular responses to denatured and aggregated proteins. Ann N Y Acad Sci. 2005; 1066:181-221. [PubMed: 16533927]

Navon A, Ciechanover A. The $26 \mathrm{~S}$ proteasome: from basic mechanisms to drug targeting. J Biol Chem. 2009; 284:33713-33718. [PubMed: 19812037]

Neumann M, Sampathu DM, Kwong LK, et al. Ubiquitinated TDP-43 in frontotemporal lobar degeneration and amyotrophic lateral sclerosis. Science. 2006; 314:130-133. [PubMed: 17023659]

Prouty WF, Karnovsky MJ, Goldberg AL. Degradation of abnormal proteins in Escherichia coli. Formation of protein inclusions in cells exposed to amino acid analogs. J Biol Chem. 1975; 250:1112-1122. [PubMed: 1089651] 
Qian SB, Zhang X, Sun J, Bennink JR, Yewdell JW, Patterson C. mTORC1 links protein quality and quantity control by sensing chaperone availability. J Biol Chem. 2010; 285:27385-27395. [PubMed: 20605781]

Reddy PH. Amyloid precursor protein-mediated free radicals and oxidative damage: implications for the development and progression of Alzheimer's disease. J Neurochem. 2006; 96:1-13. [PubMed: 16305625]

Ritson GP, Custer SK, Freibaum BD, et al. TDP-43 mediates degeneration in a novel Drosophila model of disease caused by mutations in VCP/p97. J Neurosci. 2010; 30:7729-7739. [PubMed: 20519548]

Rodgers KJ, Shiozawa N. Misincorporation of amino acid analogues into proteins by biosynthesis. Int J Biochem Cell Biol. 2008; 40:1452-1466. [PubMed: 18329946]

Rosenthal GA, Reichhart JM, Hoffmann JA. L-canavanine incorporation into vitellogenin and macromolecular conformation. J Biol Chem. 1989; 264:13693-13696. [PubMed: 2760038]

Ross CA, Poirier MA. Protein aggregation and neurodegenerative disease. Nat Med. 2004; 10(Suppl):S10-17. [PubMed: 15272267]

Sasaki S, Takeda T, Shibata N, Kobayashi M. Alterations in subcellular localization of TDP-43 immunoreactivity in the anterior horns in sporadic amyotrophic lateral sclerosis. Neurosci Lett. 2010; 478:72-76. [PubMed: 20447446]

Schmuck G, Röhrdanz E, Tran-Thi QH, Kahl R, Schlüter G. Oxidative stress in rat cortical neurons and astrocytes induced by paraquat in vitro. Neurotox Res. 2002; 4:1-13. [PubMed: 12826488]

Thomas GP, Mathews MB. Alterations of transcription and translation in HeLa cells exposed to amino acid analogs. Mol Cell Biol. 1984; 4:1063-1072. [PubMed: 6610822]

Trotter EW, Berenfeld L, Krause SA, Petsko GA, Gray JV. Protein misfolding and temperature upshift cause G1 arrest via a common mechanism dependent on heat shock factor in Saccharomycescerevisiae. Proc Natl Acad Sci U S A. 2001; 98:7313-7318. [PubMed: 11416208]

Trotter EW, Kao CM, Berenfeld L, Botstein D, Petsko GA, Gray JV. Misfolded proteins are competent to mediate a subset of the responses to heat shock in Saccharomyces cerevisiae. J Biol Chem. 2002; 277:44817-44825. [PubMed: 12239211]

Uversky VN. Alpha-synuclein misfolding and neurodegenerative diseases. Curr Protein Pept Sci. 2008; 9:507-540. [PubMed: 18855701]

Watowich SS, Morimoto RI. Complex regulation of heat shock- and glucose-responsive genes in human cells. Mol Cell Biol. 1988; 8:393-405. [PubMed: 3275876]

Watts LT, Rathinam ML, Schenker S, Henderson GI. Astrocytes protect neurons from ethanol-induced oxidative stress and apoptotic death. J Neurosci Res. 2005; 80:655-666. [PubMed: 15880562]

Wójcik C, Yano M, DeMartino GN. RNA interference of valosin-containing protein (VCP/p97) reveals multiple cellular roles linked to ubiquitin/proteasome-dependent proteolysis. J Cell Sci. 2004; 117(Pt 2):281-292. [PubMed: 14657277]

Zagari A, Némethy G, Scheraga HA. The effect of the L-azetidine-2-carboxylic acid residue on protein conformation. I. Conformations of the residue and of dipeptides. Biopolymers. 1990; 30:951-959. [PubMed: 2092823]

Zhang YJ, Xu YF, Cook C, Gendron TF, Roettges P, Link CD, Lin WL, Tong J, Castanedes-Casey M, Ash P, Gass J, Rangachari V, Buratti E, Baralle F, Golde TE, Dickson DW, Petrucelli L. Aberrant cleavage of TDP-43 enhances aggregation and cellular toxicity. Proc Natl Acad Sci U S A. 2009; 106:7607-7612. [PubMed: 19383787]

Zhu X, Lee HG, Casadesus G, Avila J, Drew K, Perry G, Smith MA. Oxidative imbalance in Alzheimer's disease. Mol Neurobiol. 2005; 31:205-217. [PubMed: 15953822] 
A
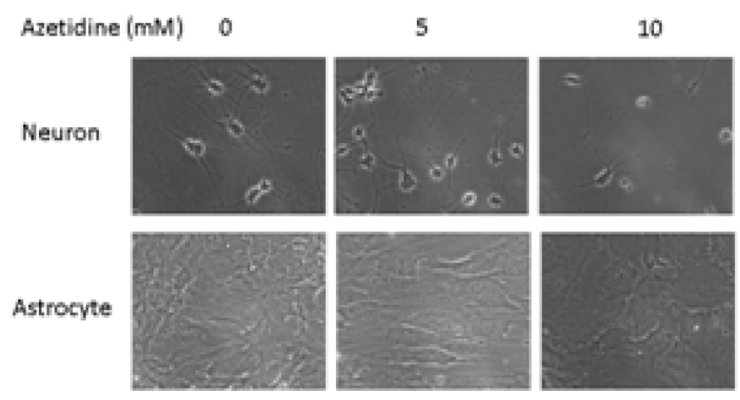

$A Z C$

B

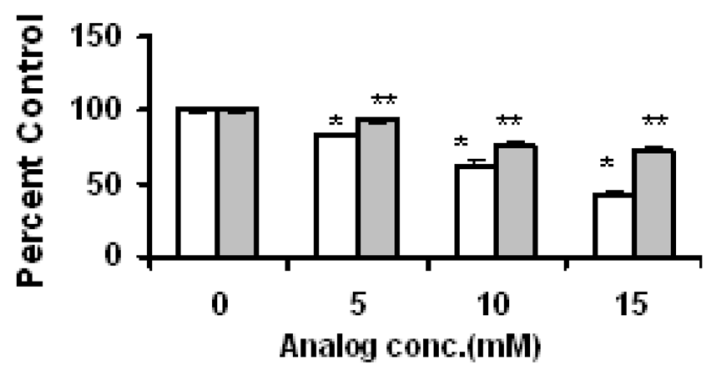

C

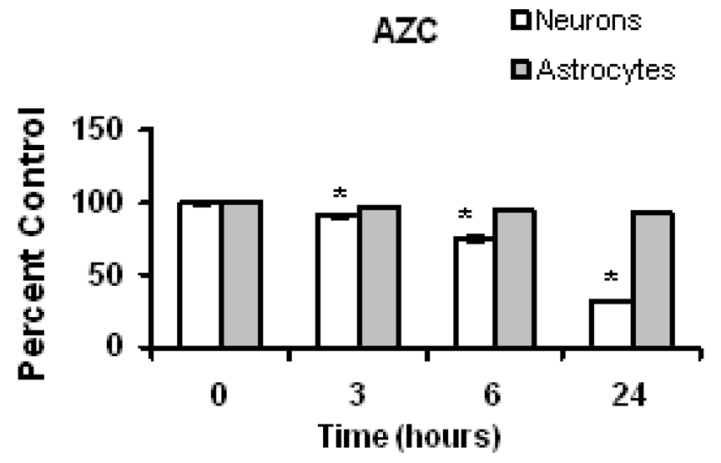

Figure 1. Amino acid analog treatment induces dose and time dependent cell death in primary rat neurons as compared to astrocytes

Cells were treated with increasing concentrations of the amino acid analog, AZC (A \& B) for 3 hours or the cells were treated with $5 \mathrm{mM} \mathrm{AZC}(\mathbf{C})$ for the indicated time intervals. Cell viability was analyzed after post treatment. Neurons were observed to have significantly higher levels of cell death in response to increasing concentrations of analog treatment as compared to astrocyte cultures. Cells treated with $5 \mathrm{mM}$ of analog showed time dependent cell death with 24 hours of treatment $(\mathbf{C})$, inducing more than $50 \%$ of cell death in neurons. Results using morphological criteria as well as nuclear condensation/fragmentation gave nearly identical results. Data $(\mathbf{B} \& \mathbf{C})$ are presented as the mean and S.E.M. of results from three different sets of independent experiments $(\mathrm{n}=5)$. $* p$ and ${ }^{* *} p<0.05$ compared to the untreated neurons and astrocytes respectively. 


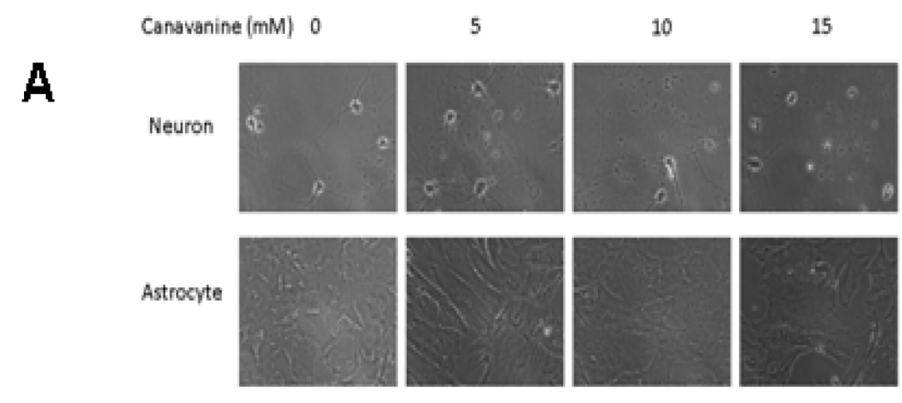

Can DNeurons

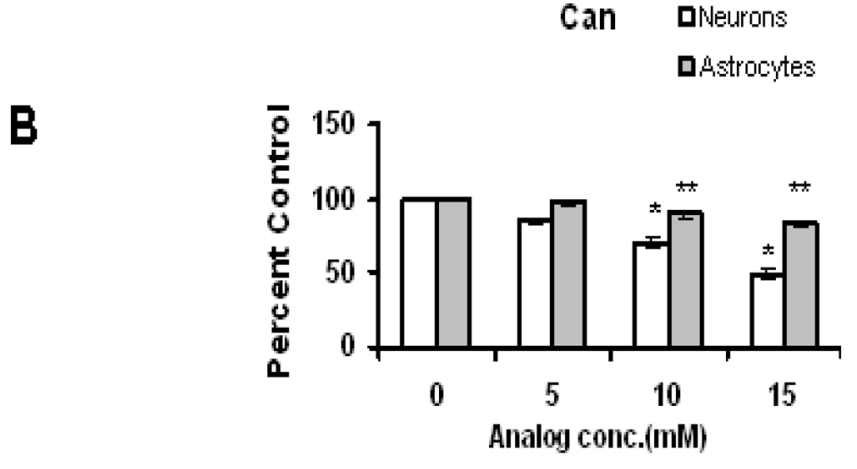

Can alveurons

C

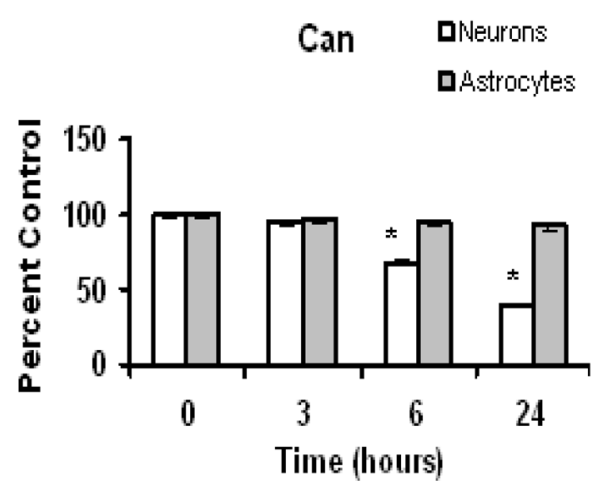

Figure 2. Amino acid analog treatment induces dose and time dependent cell death in primary rat neurons as compared to astrocytes

Cells were treated with increasing concentrations of the amino acid analog, Canavanine (A $\& \mathbf{B})$ for 3 hours or the cells were treated with $5 \mathrm{mM}$ Canavanine (C) for the indicated time intervals. Cell viability was analyzed after post treatment. Neurons were observed to have significantly higher levels of cell death in response to increasing concentrations of analog treatment as compared to astrocyte cultures. Cells treated with $5 \mathrm{mM}$ of analog showed time dependent cell death with 24 hours of treatment $(\mathbf{C})$, inducing more than $50 \%$ of cell death in neurons. Results using morphological criteria as well as nuclear condensation/ fragmentation gave nearly identical results. Data $(\mathbf{B} \& \mathbf{C})$ are presented as the mean and S.E.M. of results from 5 different sets of independent experiments $(\mathrm{n}=5)$. $* p$ and $* * p<0.05$ compared to the untreated neurons and astrocytes respectively. 

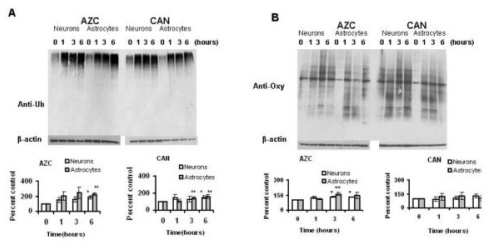

Figure 3. The levels of ubiquitinated and oxidized proteins are increased in time dependent manner following analog treatment

Rat primary cortical neurons and astrocyte cultures were analyzed for the levels of ubiquitinated (A) and oxidized proteins (B) following treatment with 5mM AZC or Canavanine for 3 hours. Results showed an increase in ubiquitination and oxidation levels with the increase in time of treatment. Beta actin was used to show equal loading of protein lysates. Data are presented as the mean and S.E.M. of results from five independent experiments. ${ }^{*} p$ and $* * p<0.05$ compared to the untreated neurons and astrocytes respectively. 
A

Neurons

Astrocytes

Anti-Hsp70

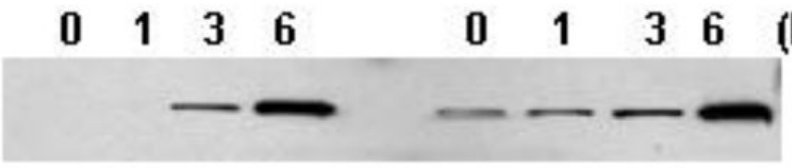

(hrs)

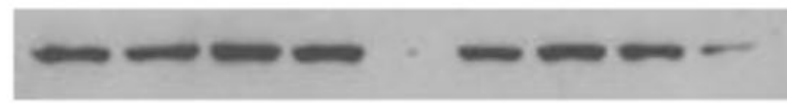

AZC

\author{
$\beta$-actin \\ Anti-Hsp70 \\ $\beta$-actin \\ C
}

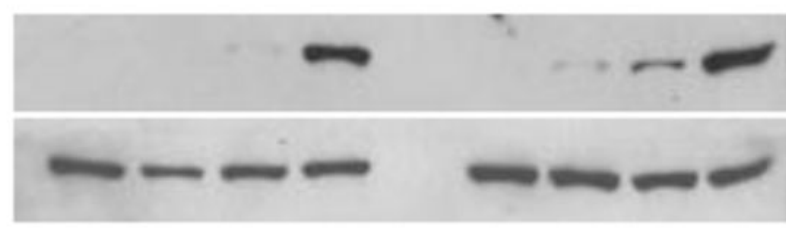

CAN

Anti-Hsp40

$\beta$-actin

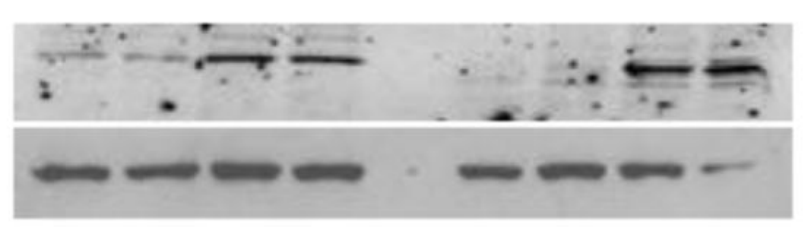

AZC

D

\title{
Anti-Hsp40 \\ $\beta$-actin
}
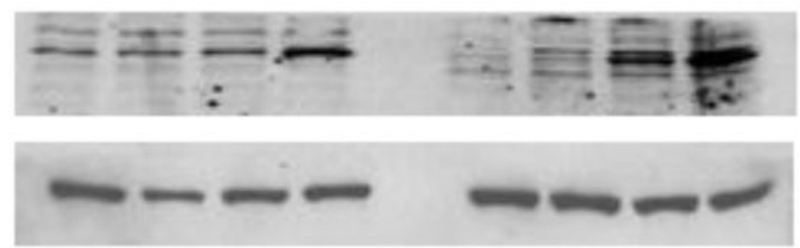

\section{CAN}

Figure 4. Induction of heat shock proteins in neurons and astrocytes following time course treatment with amino acid analogs

Lysates from rat primary cortical neurons and astrocyte cultures were analyzed by Western blotting for the levels of heat shock proteins HSP70 (A\& B) and HSP 40 (C \& D) following amino acid analog treatment, with $5 \mathrm{mM}$ AZC or Canavanine, for different time intervals. Beta actin was used to show equal loading of protein lysates. Data represents results from five independent experiments done under similar conditions. See supplementary Figure 1 for quantification. 

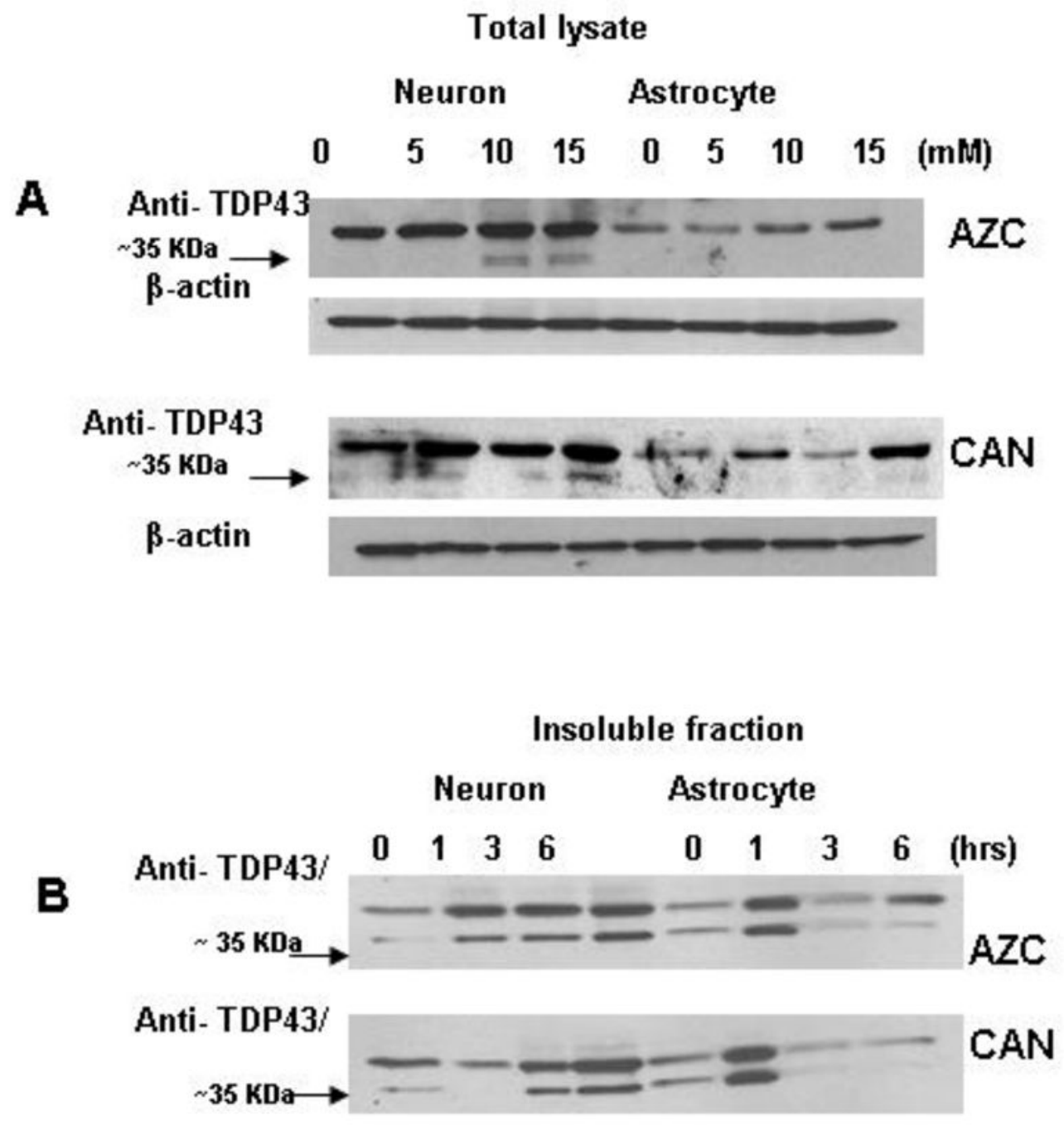

Figure 5. Levels of TDP43 in neurons and astrocytes following treatment with amino acid analogs

Whole cell lysates (A) from rat primary cortical neurons and astrocyte cultures were analyzed by western blotting for the levels of TDP 43 following treatment with different concentrations of amino acid analog, AZC or Canavanine for 3 hours. Beta actin was used to show equal loading of protein lysates. Insoluble fractions of $(\mathbf{B})$ lysates from rat primary cortical neurons and astrocyte cultures were analyzed by western blotting for the levels of TDP 43 following treatment with $5 \mathrm{mM}$ amino acid analog, AZC or Canavanine for 3 hours. Data represents findings from five independent experiments done under similar conditions. See supplementary Figure 2 for quantification. 